\title{
Happiness, Wellbeing, and Mental Health in BHutANese Higher EducAtion: Exploring StUdent AND STAFF ExPERIENCES AND Perceptions Within a Framework of Gross National Happiness
}

\author{
Matthew J. Schuelka ${ }^{a}$ \\ Mollie Braznell \\ Matthew Leavesley \\ University of Birmingham \\ Sangay Dorji \\ Khandu Dorji \\ Karma Nidup \\ Pema Latsho \\ Royal University of Bhutan
}

\begin{abstract}
Bhutan is a country known for happiness. In the 1970s, the Fourth Druk Gyalpo [Dragon King] of Bhutan established the development philosophy of Gross National Happiness (GNH). However, using 'happiness' as a measurement of social and economic development does not mean that all Bhutanese are 'happy' themselves. Schools - including higher education - can be stressful places in Bhutan, and there is little support or resources for the mental health and wellbeing needs of students. In this article, we explore the experiences and perceptions of both students and staff across the Royal University of Bhutan in regard to wellbeing and mental health. In all, there were over 1,700 respondents to our survey. We explore the results of the survey through an Educational Values Evaluation and Design (EVED) framework to understand the complex factors that both enable and challenge GNH as a value in higher education. The results show that while many students view their happiness and wellbeing as positive overall, there are still a significant amount that experience depression, stress, social difficulties, and other forms of distress. In comparison to college staff perception of student's mental health and wellbeing, the students are more positive about their own wellbeing than the staff.
\end{abstract}

Keywords: Wellbeing, Mental Health, Bhutan, Gross National Happiness, Higher Education

\section{Introduction}

Bhutan is often characterized as the 'land of happiness' because it is the originator of the development philosophy of Gross National Happiness (GNH) - an alternative to Gross National Income. While Bhutan is a bucolic and peaceful kingdom, beautifully tucked away in the Himalayas, GNH does not guarantee that its citizens are happy. Indeed, the latest GNH Survey of Bhutan indicated that over half the country are 'unhappy' or 'narrowly happy' (Centre for Bhutan Studies, 2016). However,

a Correspondence can be directed to: m.schuelka@bham.ac.uk 
Bhutan is mindful on happiness and wellbeing in that GNH guides its policies, decision-making, and societal goals.

In Bhutan, happiness does not mean individual happiness. Rather, it means the collective happiness and wellbeing of all. In Dzongkha, the Bhutanese national language, GNH is expressed as the phrase Gyalyong Gakid Pelzom ["happiness and peace for all nations for the realization of all things good and virtuous"] (Schuelka, 2017). In terms of operationalizing GNH, all policies and government initiatives must be approved by the GNH Commission, whose mission - as enshrined in the constitution - is to ensure the centralization of the four pillars of GNH (sustainable and equitable socio economic development; preservation and promotion of cultural heritage; preservation and sustainable use of the environment; and good governance) and the nine domains of GNH (psychological wellbeing, health, education, culture, time use, good governance, community vitality, ecological diversity and resilience, and living standards).

The youth of Bhutan - particularly those in young adulthood - are often caught between Bhutan's aspirations and realities. They are extremely proud of GNH and of Bhutan as a whole, but they are also expected to make a modern living in a capitalist society; to become educated and get a good job to ensure success and financial stability for their families. This is the reality for many young adults around the world, but in Bhutan it is particularly pronounced as the country has experienced rapid societal, economic, and cultural changes in only a few decades. As Willis memorably writes, "Young people are unconscious foot soldiers in the long front of modernity, involuntary and disoriented conscripts in battles never explained" (2003, p. 390). Nowhere is the stress and anxiety of youth in a transitioning society more pronounced than at the tertiary level of education (Field, et al. 2012; Gündogdu, 2010; Rickinson, 1998).

The research presented here is an exploration of the mental health, wellbeing, and happiness of young adults in Bhutan at the tertiary level of education. In this article, we will explore the results of a survey conducted across the entire Bhutanese higher education sector. Through the analysis and results of the survey, we argue that higher education institutions are crucial in promoting the mental health and wellbeing of young adults in a 'modern' society, but also reflect one aspect of a complex web of factors that influence the value of GNH in higher education. Higher education institutions also need to better integrate with existing community resources and local resiliency support networks, as well as provide more relevancy in aligning with socio-economic realities. We use an Educational Values Evaluation and Design (EVED) framework (Schuelka, forthcoming; Schuelka $\&$ Sherab, forthcoming) to support this argument.

In the article below, we will first provide a brief overview of the context of education and culture in Bhutan. Next, we will provide a succinct definition of the EVED theoretical framework that guides the analysis of the survey results. We will then explain the survey design and methodology. Following that, we will present the data and analysis of the survey from both university students and staff, and conclude with a discussion on the results and implications for the future.

\section{Understanding the Context of Education and Culture in Bhutan}

Bhutan is a small, extremely mountainous country located entirely in the Himalayas between China (Tibet) and India. Bhutan was never colonized, and remained a remote, feudal, and agrarian society until the $20^{\text {th }}$ century. Bhutan's royal family, since 1910 , have initiated and overseen an extraordinary transition to a modern socio-economic state, including the peaceful introduction of democracy to Bhutan in 2006.

Until the Royal Government of Bhutan's First Five-Year Plan in 1959, education in Bhutan was almost entirely monastic and served a sliver of the population. Buddhist monasteries were the only source of formal literacy development - in religious classical Tibetan - and the vast majority of the general Bhutanese population could not read or write in any language. With the advent of planned socio-economic development programs beginning in the 1960s, the education sector received priority from the government as a means for human capital development (Schuelka \& Maxwell, 
2016). Today, the education structure in Bhutan can be divided into three tiers: formal (secular) education, monastic (religious) education, and non-formal education.

Education is recognized both as a basic right in the national constitution, as well as a prerequisite for achieving wider national aspirations. The Royal University of Bhutan (RUB) was established in 2003. The RUB consists of 10 colleges specializing in different academic areas, as well as 2 private affiliate colleges that offer a variety of programs. In Bhutan, the colleges are spread over the entire country, the result being that higher education students attend only their specialist program and do not mix.

A key aspiration of the RUB is in the area of promoting a GNH-inspired society. The university expects all the colleges to use GNH values and principles as the educational foundation for degree programs. Since the inception of Educating for Gross National Happiness (EGNH) in 2010, all the colleges under the RUB were instructed to incorporate the theme of GNH in different modules and to deliver it accordingly in the classroom. Most recently, many staff were trained on universal human values both within the country as well as outside the country, and this training is done as part of the RUB's strategic plan (Pema Thinley, 2016).

While the RUB is certainly aspirational in its planning and policies, there are critical challenges that the RUB faces both internally and externally. Education in Bhutan, in general, is slow to respond to rapid changes in society and the economy (Sonam Kinga, 2005). The RUB has made enormous progress in a short amount of time, but still could be more innovative and fleet-of-foot in being societally and economically aligned and future-orientated (Schofield, 2016). While change may be slow, the RUB continues to focus on key areas of development, particularly when it comes to its role in inculcating GNH values. This study, and accompanying project, serves to shine a light on these values as they are realized in the happiness and wellbeing of higher education students and staff. In this next section, we will explain our theoretical framework that helps guide our analysis and understanding of the factors that promote and hinder the realization of GNH in Bhutanese higher education students.

\section{The Educational Values Evaluation and Design (EVED) framework}

Any educational system or institution that sets out to promote certain societal values and attributes will find itself within a nested series of complex societal systems. One way to understand the elements that inform values within a complex educational system is the Educational Values Evaluation and Design (EVED) framework proposed by Schuelka and Kezang Sherab (forthcoming). This framework itself originated from a multi-year study of educational values in Bhutan, but can be applied to any complex educational system. The visualization of the framework is in Figure 1 below:

\section{Figure 1: The Educational Values Evaluation and Design Framework}
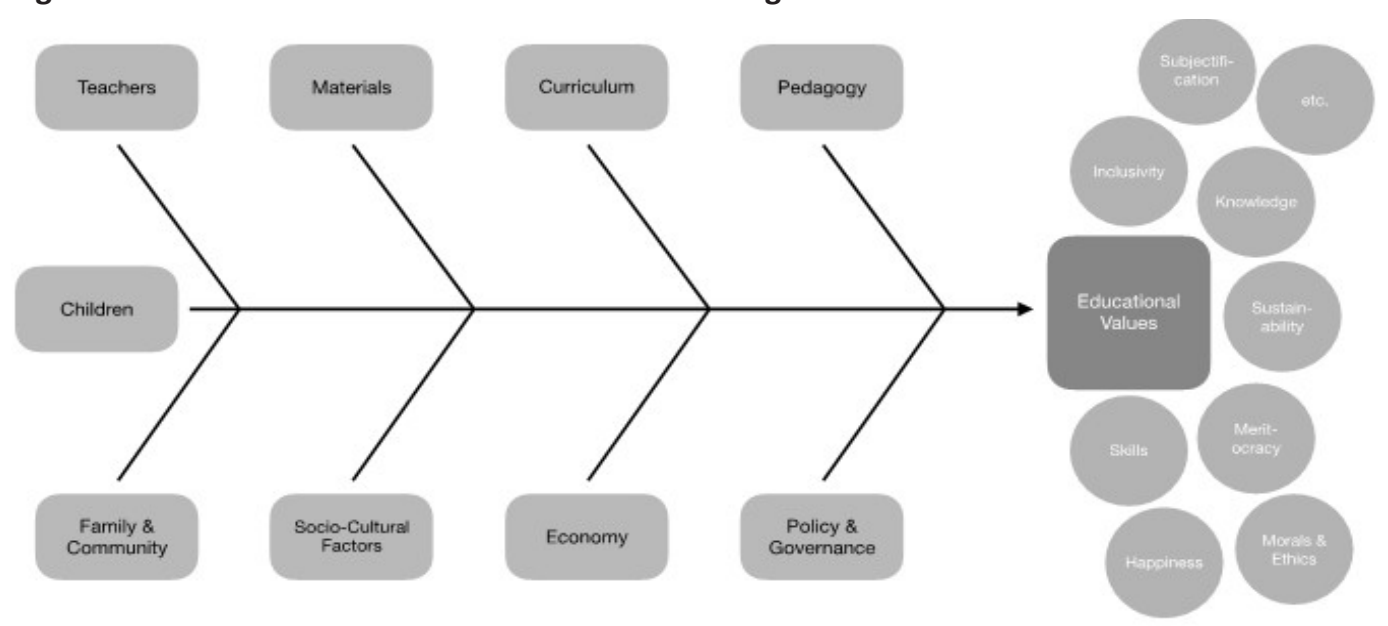
Succinctly, the EVED framework identifies various elements that influence values perpetuated within an educational system. Note that this is not an exhaustive list of elements, and any research that uses the EVED framework may add or subtract elements for the purposes of their own analyses. The elements themselves are also simple categories that may be further broken-down into subcategories. The elements are also inter-connected, and do not exist apart from other elements. The EVED framework can be used to identify misalignments and disjunctures of various elements in promoting certain values. For example, Schuelka (forthcoming) used the EVED framework to analyze various elements of the Bhutanese educational system that promote and challenge inclusion as an educational value. He found that misalignments between curriculum, teacher role identification, pedagogical practices, materials, and socio-economic incentives were not aligned with inclusive education policy and thus the value of inclusion in the Bhutanese educational system cannot be fully realized (Schuelka, forthcoming). The EVED framework can also be used pro-actively, in that values in an educational system can be deliberately designed when all of the elements are considered. For example, GNH as a value in higher education needs to not only exist in policy, but also be embedded in curriculum, embodied by teachers' pedagogical techniques and attitudes, and supported by the community to name only a few necessary elements. Based on the results of our survey, certain elements from the EVED framework will be considered and discussed. In the next section, we will explain how we went about collecting data for the survey.

\section{Survey Design and Methodology}

The mixed-method survey presented in this article is part of a larger project to support the establishment of counselling and wellbeing programs and centers in 9 colleges within the RUB. The $10^{\text {th }}$ college - Yonphula Centenary College - was only just founded at the inception of our project and not included. There is only one other university in Bhutan - the Khesar Gyalpo University of Medical Sciences (KGUMS) - which is small and specialized. The KGUMS was also not included in our survey.

The online questionnaire survey collected quantitative and qualitative data in the form of closed-ended and open-ended questions. The questionnaire was in English, as this is the language of instruction and used widely by students and education professionals within schools in Bhutan. Our research design can be aptly categorized as 'convergent parallel mixed-methods' (Creswell, 2014) as the quantitative and qualitative data were collected within the same survey. These methods are within the single-country case study of Bhutanese higher education. As we wanted to ascertain participants' perceptions and experiences, our survey methodology was primarily emergent. However, we did statistical analysis to determine if dependent variable answers were influenced by factors such as age, gender, experience, and area of study.

The open-ended questions were analyzed using thematic analysis (Braun \& Clarke, 2006). This process involved identifying emerging patterns and themes within the data to gain a clear understanding of the most common responses to the questions. For example, when students were asked whether they knew anyone in their college who had contemplated or attempted suicide they were offered an additional option to provide further details regarding their answer. From these responses four themes emerged, these themes were personal experience of suicide, reasons for suicide, action to be taken to reduce risk, and awareness. These themes were further broken down into sub-themes for clarity. The most common theme for this question was awareness. This occurred in $57 \%$ of the responses, and within that theme $60 \%$ of these responses were about not knowing of any suicide cases.

The questionnaire survey was distributed to all students and staff in the RUB (approx. 9,070 undergraduate students; 463 staff). The survey was completed by 1,364 students ( $15 \%$ response rate) and 292 staff members (63\% response rate). The survey questions were modelled on a similar validated survey conducted on Welsh university students (Williams, et al., 2017). This Welsh study by Williams, et al. examined predictors of positive well-being, negative mental health, and cognitive function; very similar to our own aims and objectives. Our questionnaire consisted of 64 questions, 
eliciting both qualitative open-ended, and quantitative closed-ended, responses utilising a Likert scale. The data collected from the Likert scales was analysed using the mean scores of responses.

One potential limitation of our study was in choosing to analyse mean scores from ordinal data, which can present challenges (Sullivan \& Artino, 2013; Hasson \& Arnetz, 2005). The first step in addressing this, as argued by Jamieson (2004), is for the authors to draw attention to the caution of analysing Likert scale data in this way. This may be a limitation of our research analysis, but we feel that Likert scale means best represented the data for the purposes of the study, as supported by Willits, Theodori, and Luloff (2016, p. 133) in their assertion that "responses to Likert type items can also be treated as interval scales." Another limitation in our study was a relatively small response rate from students (15\%), although we had 1,364 returned questionnaires which is still a confidence interval of $4 \%$ with a $99 \%$ confidence level.

The survey protocol followed standard research ethics guidelines and was approved by all institutions involved. Survey participants were assured the right to anonymity, privacy, and data protection. Participants gave their written consent and were allowed to withdraw their personal data at any time during a 6-month period between data collection and data analysis. Being that this was an online survey, there was no harm to the participants, nor was there any inducement.

\section{Results of the Student Survey}

The aim of the student survey was to discover more about student wellbeing and happiness across the 9 colleges of the RUB sampled. During the analysis phase, the questions were sorted into 9 categories which facilitated thematic analysis of the various aspects of student wellbeing. The categories are as follows:

1. Student health and wellbeing

2. Student relationships

3. Student capabilities

4. Student responses to stress

5. Student life

6. Student support networks

7. Student perception of substance misuse and suicidal ideation

8. Student identified academic factors

9. Student opinions

The student surveys began with demographic questions. The findings from this data indicated the following demographic information:

Table 1. Student survey response demographic information

\begin{tabular}{|l|l|}
\hline \multirow{3}{*}{ Gender: } & Female (50\%) \\
\cline { 2 - 2 } & Male (48\%) \\
\cline { 2 - 2 } & Undisclosed (2\%) \\
\hline \multirow{3}{*}{ Age: } & $\begin{array}{l}\text { The mean age of respondents was } 24 \text { with ages ranging between 18- } \\
\text { 45, however most were aged between 18-27. }\end{array}$ \\
\hline & JNEC - Jigme Namgyel Engineering College (16\%) \\
\cline { 2 - 2 } & CLCS - College of Language and Culture Studies (16\%) \\
\cline { 2 - 2 } & SCE - Samtse College of Education (15\%) \\
\cline { 2 - 2 } & CST - College of Science and Technology (15\%) \\
\cline { 2 - 2 } & SHER - Sherubtse College [Humanities] (14\%) \\
\cline { 2 - 2 } & CNR - College of Natural Resources (11\%) \\
\hline
\end{tabular}


Table 1. Student survey response demographic information (continued)

\begin{tabular}{|c|c|}
\hline & PCE - Paro College of Education (8\%) \\
\hline & GCIT - Gyalpozing College of Information Technology (3\%) \\
\hline & GCBS - Gaeddu College of Business Studies (2\%) \\
\hline \multirow[t]{5}{*}{ Years of study: } & $1^{\text {st }}$ year $(31 \%)$ \\
\hline & $2^{\text {nd }}$ year $(35 \%)$ \\
\hline & $3^{\text {rd }}$ year $(17 \%)$ \\
\hline & $4^{\text {th }}$ year $(4 \%)$ [Courses are typically only three years in length] \\
\hline & other $(6 \%)$ \\
\hline \multirow[t]{4}{*}{ Relationship status: } & Single (73\%) \\
\hline & Long-term relationship (19\%) \\
\hline & Married (6\%) \\
\hline & Other $(2 \%)$ \\
\hline \multirow[t]{4}{*}{ Living arrangements: } & College dormitory (87\%) \\
\hline & Private accommodation with other students (6\%) \\
\hline & Private accommodation alone (4\%) \\
\hline & Living with family (3\%) \\
\hline \multirow[t]{2}{*}{ Children: } & Do not have children (96\%) \\
\hline & Do have children (4\%) \\
\hline \multirow[t]{2}{*}{ How studies are financed: } & Government funded (84\%) \\
\hline & Self-funded (16\%) \\
\hline
\end{tabular}

Participants were asked to respond using a 1-10 Likert scale, where 1 represented a negative response and 10 was positive. However, some questions were negatively phrased, and these values were reverse-scored accordingly when determining the mean response for each category. $A$ multivariate analysis of variance (MANOVA) was used to analyze the independent variables against each student category. Independent variables included College of Study, Gender, Age, and Year of Study.

Significant findings from the analysis were found in Student Life (student category 5) when analyzed against the independent variable of College of Study. This will be expanded on below. However, in looking at the means from student categories 1-6 across colleges, nearly all differences between colleges are statistically insignificant. This can be seen in Figure 2 below:

\section{Category 1: Student Health and Wellbeing}

Findings indicated good levels of health and wellbeing amongst participants, with a combined mean response of 6.44 out of 10 . However, incongruities were discovered when participants were asked in one question whether they feel they have low self-esteem, and in another whether they have positive self-esteem. This discrepancy indicated that students may tend towards answering positively phrased questions positively, and vice versa.

\section{Category 2: Student Relationships}

Most students felt positive about their relationships with others. The combined mean for this category was 6.97 out of 10. Participants were asked about their social support and how well they 
Figure 2. Mean scores from student survey, arranged by college and category

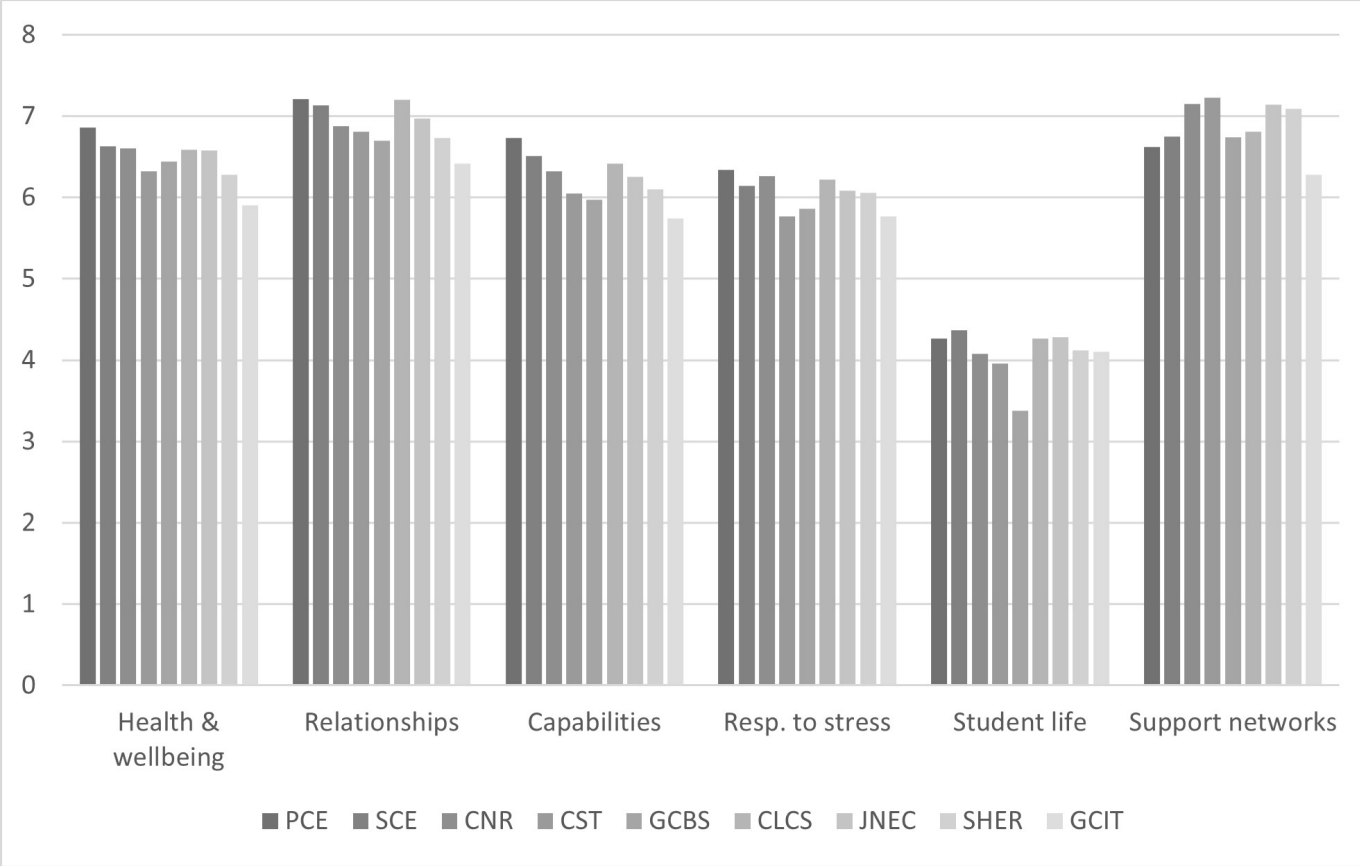

get on with others. However, again when participants were asked the same question phrased both positively and negatively discrepancies arose.

\section{Category 3: Student Capabilities}

Overall, it could be deduced that students were generally confident in their abilities to perform academically. When respondents were asked about their problem solving and motivation, the combined mean produced was 6.29 out of 10 . When asked about their interest in new ideas, they demonstrated high levels of academic enthusiasm with a mean score of 7.37/10.

\section{Category 4: Student Responses to Stress}

The findings indicate that students were likely able to respond to stress in a healthy way, and less likely to engage in unhelpful behaviors such as drinking/smoking/drug-use to avoid their problems. The responses generated a mean score of 6.10 out of 10 .

\section{Category 5: Student Life}

Students tended to have negative experiences of student life. This category generated the lowest combined mean of 4.2 out of 10 . When asked about challenges to their development and time pressures, respondents indicated that this was a significant issue, with a mean score of 3.65/10 for both questions. These results highlight that the area of strongest student dissatisfaction lies in their student life, whereby they feel high levels of time pressure, challenges to development, and academic dissatisfaction. This will be further explored in the discussion section.

\section{Category 6: Student Support Networks}

Along with student relationships (category 2), this category scored the highest mean of 6.94 out of 10. In this category, students were asked about their access to tangible and emotional support and were 
later asked to disclose who they who they can/would discuss their problems with. After analyzing the responses to this question, it was found that the top 3 persons students see to discuss their problems were parents (45\%), fellow classmates (14\%), and friends outside of their college (14\%).

\section{Category 7: Student Perceptions of Substance Misuse and Suicide Ideation}

Overall, students did not identify substance misuse and suicide ideation to be significant challenges in Bhutanese higher education from their personal experience. However, many respondents were concerned about the general consequences of drug/alcohol over-use and called for action from the university to resolve issues, along with the introduction of counselling and guidance services. For example, one respondent wrote "They know well about its side effects...therefore if some counselling are provided for them...so that they would stop" [all quotes from respondents are provided without edit].

Respondents talked about not knowing of any suicide cases, with many stating that it does not happen at all. However, among students who talked of experiences of suicide, although most comments were about other people in their lives, there were a number of students who confessed to having a personal experience of suicide ideation. Furthermore, relationship issues were identified as the most common answer given about reasons for suicide ideation, with college/family pressures and depression also being a reoccurring factor. Moreover, community action/support along with counselling/mental health support were stated as actions that could be taken to reduce suicide risk. For example, one respondent wrote, "If better counselling could be provided and if therapy could be provided for those suffering from mental issues, it would be nice. Some counsellors don't feel genuine."

\section{Category 8: Student Identified Academic Factors}

On average, students expressed some concern over their academics and academic support. Students felt that the workload was not manageable and that the expectations from tutors was too high. They did not feel comfortable expressing their ideas and opinions in class, which is unsurprising given the pervasiveness of teacher-centered pedagogy and strict lecture formatting. It is also notable that securing a job after college was of the upmost concern, and there was general pessimism about this - particularly of the college's ability to help them with employment. The mean student responses across all colleges are demonstrated in Figure 3 below:

\section{Figure 3. Student mean scores on academic factors}

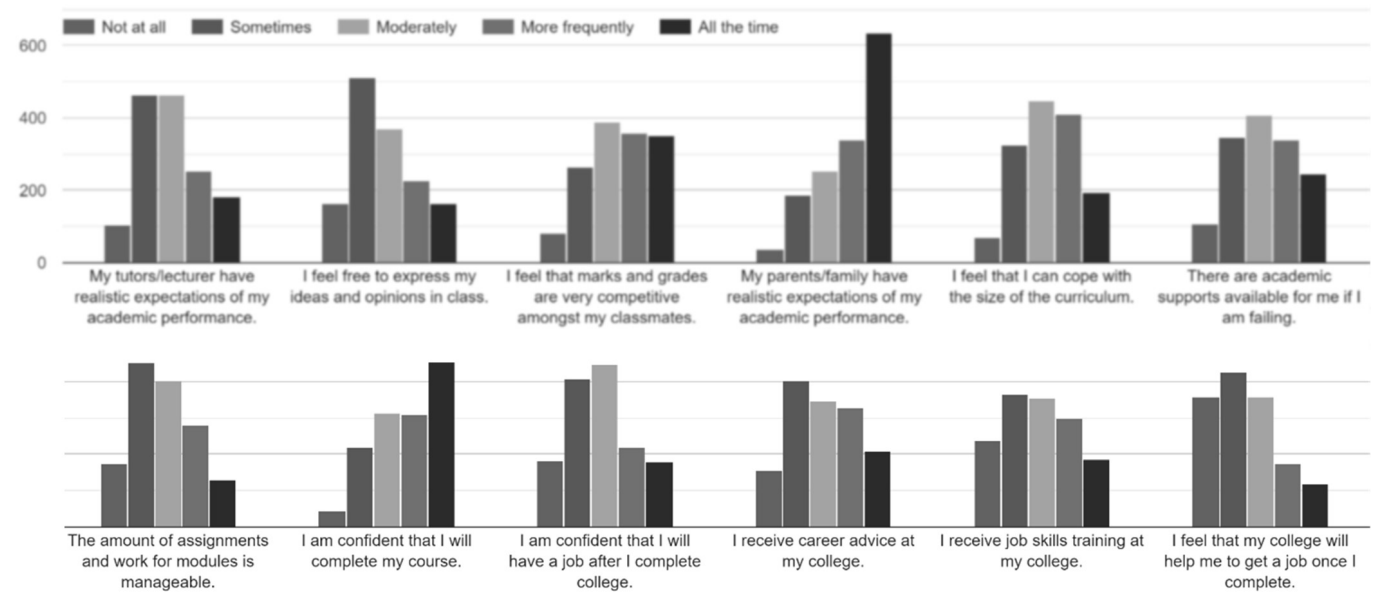




\section{Category 9: Student Opinions}

At the end of the survey participants were asked to respond to 7 open-ended questions. Students were first asked about the existing support offered by the colleges; the comment most frequently mentioned here was that spiritual support was provided, and this was closely followed by peer counselling. When students were asked what kind of wellbeing support they would like to see offered at their college; counselling received the most number of mentions, particularly counselling offered by trained professionals. Students were also asked what kind of academic support they would like to be offered; here respondents emphasized the need for better quality teaching and more learning resources. For example, one respondent wrote "Quality of teaching should increase rather than reading slide by tutors" and another wrote "Monitor teaching standard since some lecturer just come to class and doesn't teach anything." Students were also asked to provide thoughts on what they would like to see from their counselling center. Most responses to this question asked for general counselling services, particularly solutions to their problems. However, students also expressed a need for the service to be confidential and approachable, with guidance on careers and stress management. Students were also asked where in the community they could go for wellbeing support; most responses to this question featured a medical-psychological approach and indicated that they would go to the hospital/basic care unit.

When respondents were asked what the most serious mental health challenges are for youth in Bhutan, the top comment was about depression, followed by stress and low self-esteem. Substance abuse and financial/employment worries were also reoccurring amongst the responses, with pressures from family, education, and relationships also being frequently mentioned.

Finally, respondents were asked for their opinion on whether college students in Bhutan are happy. Most responses stated that yes, students are happy, with the most common reason for this being that students needs are met because they have free education. Of those who stated students were unhappy, or provided a mixed response, the most common reason stated for this was relating to a negative college environment and worries about limited job opportunities. Furthermore, college facilities were also frequently mentioned as being poor and not up to student expectations. For example, one respondent wrote, "Maybe [students are happy] because students are mostly provided free tuition but the facilities provided are only satisfactory," while another wrote, "No [students are not happy], because after training for more than 3 years they are left without job and less facilaties [sic] compare to other college."

\section{Results of the Staff Survey}

The aim of the staff survey was to help understand how staff perceive the happiness and wellbeing of university students in Bhutan. In particular, the data from the survey showcases how staff at the RUB perceive the challenges and issues young people face during their college experience. Staff were also questioned on their own happiness and wellbeing while working for the RUB. The staff survey had 36 questions that teaching and non-teaching staff at the RUB answered. In total, 292 staff members responded. During the analysis phase, the questions were sorted into 10 categories which facilitated thematic analysis of the various aspects of staff and student wellbeing. The categories are as follows:

1. Staff perception of student health and wellbeing

2. Staff perception of student relationships

3. Staff perception of student capabilities

4. Staff perception of student stress

5. Staff health and wellbeing

6. Staff job satisfaction 
7. Staff support networks

8. Staff perception of substance misuse and suicidal ideation

9. Staff identification of mental health challenges for Bhutanese youth

10. Staff perception of the happiness of students in Bhutan

The independent variables identified to analyze against each quantitative category included college of employment, gender, staff type, and years of service. The demographic information of the respondents can be seen in Table 2 below:

Table 2. Staff survey response demographic information

\begin{tabular}{|c|c|}
\hline \multirow[t]{3}{*}{ Gender: } & Female (63\%) \\
\hline & Male (34\%) \\
\hline & Undisclosed (3\%) \\
\hline \multirow[t]{9}{*}{ College of employment: } & JNEC - Jigme Namgyel Engineering College (7\%) \\
\hline & CLCS - College of Language and Culture Studies (7\%) \\
\hline & SCE - Samtse College of Education (8\%) \\
\hline & CST - College of Science and Technology (14\%) \\
\hline & SHER - Sherubtse College [Humanities] (18\%) \\
\hline & CNR - College of Natural Resources (16\%) \\
\hline & PCE - Paro College of Education (8\%) \\
\hline & GCIT - Gyalpozing College of Information Technology (6\%) \\
\hline & GCBS - Gaeddu College of Business Studies (16\%) \\
\hline \multirow[t]{2}{*}{ Staff type: } & Teaching staff (67\%) \\
\hline & Non-teaching staff (33\%) \\
\hline \multirow[t]{2}{*}{ Years of service: } & $0-4$ years $(39 \%)$ \\
\hline & $5+$ years $(61 \%)$ \\
\hline
\end{tabular}

Analysis of the staff responses followed the same rules as analysis of the student responses, meaning that analysis for most categories was based on a Likert-scale response in which the positively and negatively scored questions were aligned in SPSS. For each category, independent variables were tested using a MANOVA. All independent variables were analyzed against each category. Significant findings from the analysis came from Categories 5 and 6, as discussed below.

\section{Category 1: Staff Perception of Student Health and Wellbeing}

Staff across all colleges perceive that students have positive self-esteem. However, staff also perceive students to be depressed. The mean score for the question 'Overall, I think that students feel that they have positive self-esteem' was 6.84/10.

\section{Category 2: Staff Perception of Student Relationships}

Staff reported that generally students get along well with others, with a mean score of 6.44 out of 10. However, female staff recorded a higher mean score indicating they are more likely to perceive students as not getting along with people $(6.21 / 10)$ compared to their male colleagues $(6.12 / 10)$. 


\section{Category 3: Staff Perception of Student Capabilities}

An above average number of staff believed that students had a disagreeable nature. Teaching staff recorded a higher mean score in answer to these questions, indicating they believe students are more disagreeable in nature $(5.92 / 10)$ compared to their non-teaching colleagues $(5.73 / 10)$. This was not a statistically significant difference between staff types. Both teaching and non-teaching staff felt that students were confident 'in their ability to solve problems that they might face in life' (6.54/10).

\section{Category 4: Staff Perception of Student Stress}

Staff perceived students to be anxious, with a mean score of 6 out of 10 . There was also a difference in perception between younger staff and those with more experience. RUB staff who have been with the university for less than a year recorded a higher mean score (5.11/10) on their perception that students employ avoidance strategies to deal with stressful situations. However, this was not statistically significant.

\section{Category 5: Staff Health and Wellbeing}

Staff from all colleges reported positivity around their physical health, but scored negatively in regards to their mental health. Three questions were analyzed together in this category by running MANOVA against each of the 4 independent variables. A significant finding using Pillai's Trace of $<0.01$ was recorded when analyzing Category 5 (Staff Health \& Wellbeing) and the independent variable (A) College of Employment. Staff from all colleges recorded a mean score of 7.36 out of 10 for their physical health, but a mean score of 4.90 out of 10 on how stressful their lives were. Staff from JNEC recorded the highest levels of stress while SCE recorded the lowest. A significant finding using Pillai's Trace of $<0.01$ was recorded. This finding highlights a disparity between mental and physical health of staff working at the RUB, as can be seen in figure 4 below.

\section{Figure 4. Staff health and wellbeing, categorized by college}

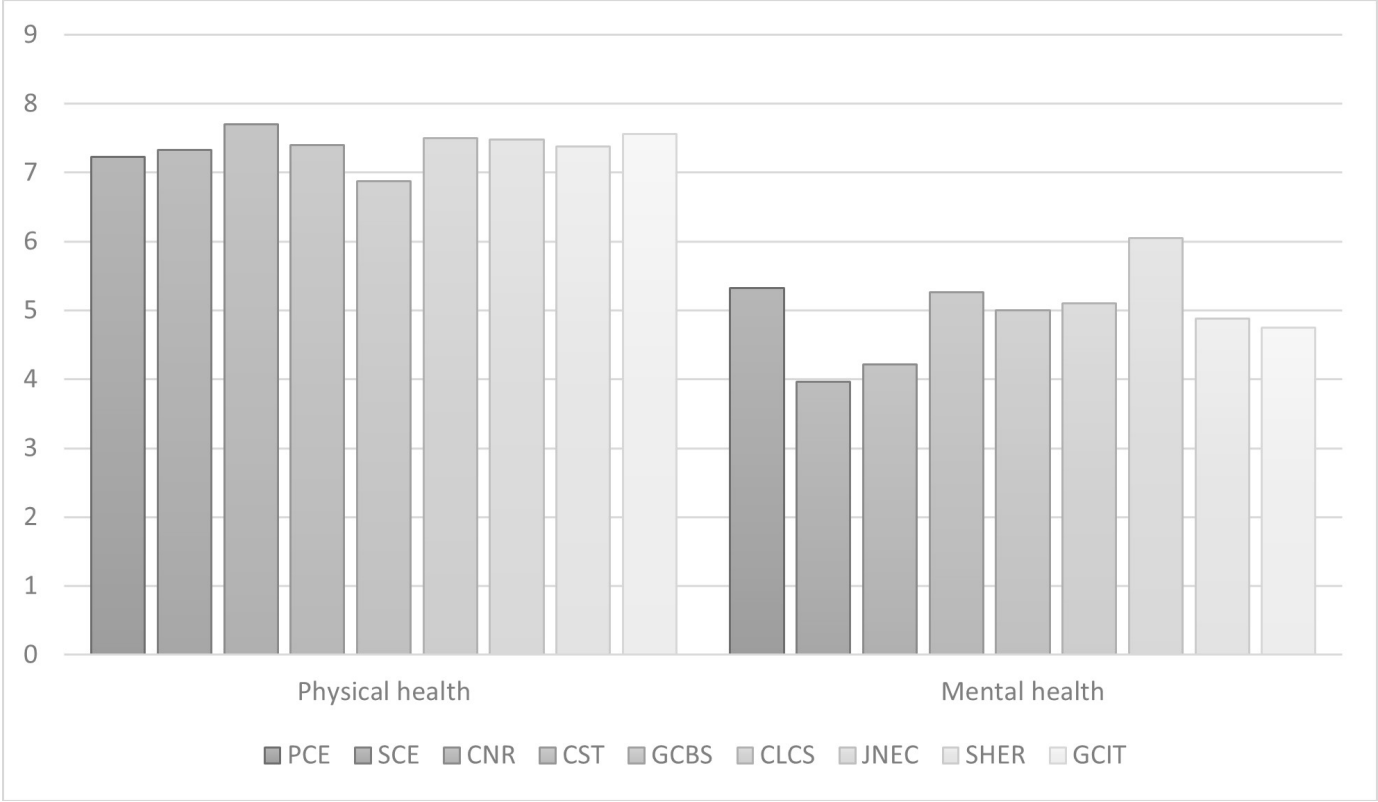




\section{Category 6: Staff Job Satisfaction}

The results of the survey from this category highlights a disparity between staff job satisfaction and having the time to complete the work assigned to them. Staff having worked at a college between 0-4 years recorded the highest mean score for time pressures and job dissatisfaction; this result highlights that staff who at the infancy in their careers feel more time pressures that directly impact how they feel about their satisfaction with their work. A significant finding using Pillai's Trace of 0.00 was recorded when analyzing Category 6 (Staff Job Satisfaction) and independent variable (A) College of Employment. A significant finding using Pillai's Trace of 0.01 was also recorded when analyzing the same category with (D) Years of Service. Staff from all 9 colleges recorded a mean score of 4.72 out of 10 for being dissatisfied with their school/work, but a mean score of 7.10 out of 10 was recorded for time pressures.

\section{Figure 5. Staff job satisfaction, categorized by years of service}

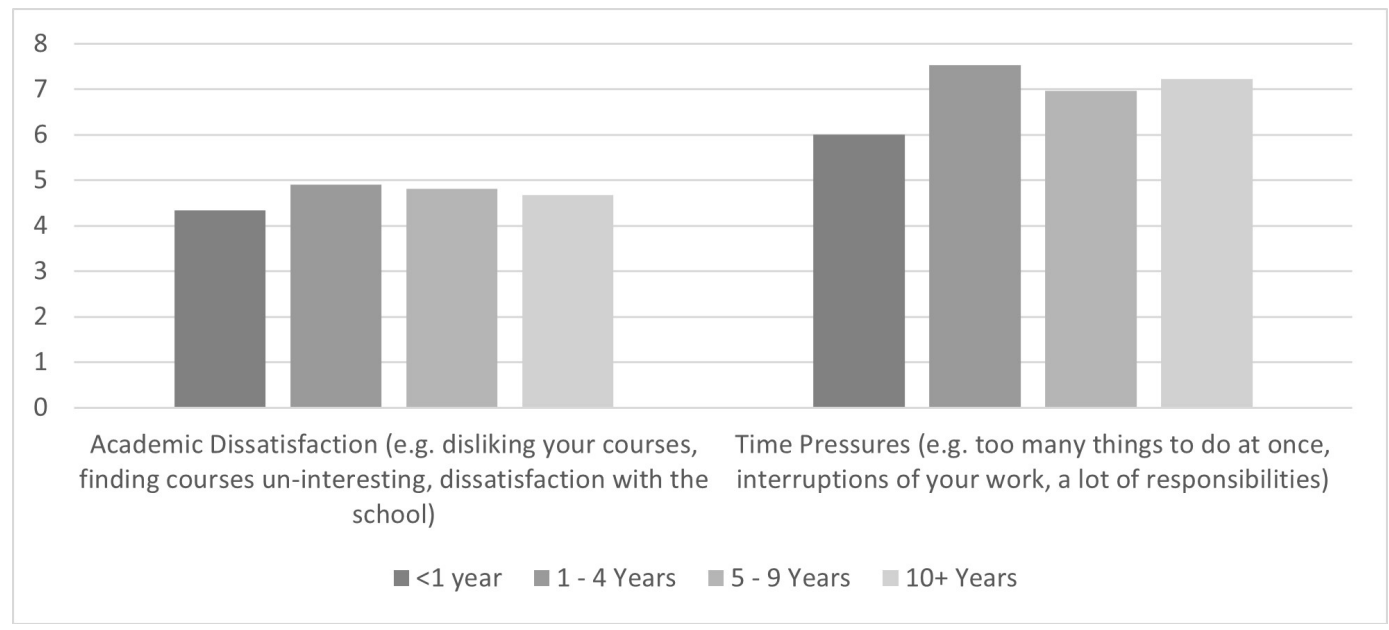

\section{Category 7: Staff Support Networks}

Female RUB staff were more likely to have a support network, as compared to their male colleagues. This can be seen in Figure 6 below.

\section{Figure 6. Staff response on support networks}

There is a person or people in my life who would provide tangible support for me when I need it

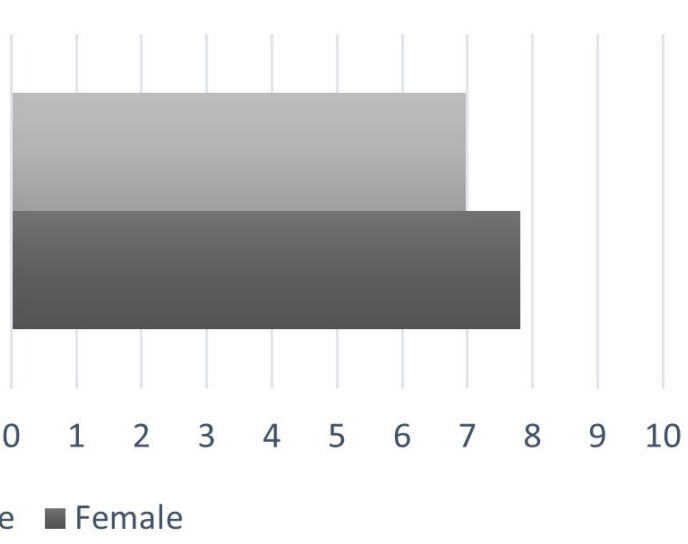




\section{Category 8: Staff Perception of Substance Misuse and Suicidal Ideation}

The majority of RUB staff members (81\%) responded that they did not know anyone in their college that had contemplated or attempted suicide. Staff were asked whether they knew someone in their college who misuses alcohol, drugs and/or tobacco - in total $13 \%$ said 'Yes,' $46 \%$ said 'Maybe,' and $41 \%$ said 'No'.

\section{Category 9: Staff Identification of Mental Health Challenges for Bhutanese Youth}

When staff were asked to identify serious challenges facing Bhutanese youth today - in an openanswer format - four themes emerged from the data. The themes that emerged were life issues; addiction, mental health, and substance misuse; identity and social stigma; and, 'being weak'. Each of these themes will be elaborated below.

For some staff, the serious challenges facing the youth of Bhutan centered around life issues relating to family, relationships, unemployment, and peer pressure. Staff articulated that family problems including poor parenting, divorce, domestic abuse, lack of support, and pressure to succeed are a serious challenge for Bhutanese youths. For example, staff participants expressed thoughts such as "In my opinion the root causes of youth issues and challenges in Bhutan... is the lack of proper parental care" and "The most serious challenges are a lack of family support." Staff mentioned that in connection with family problems, romantic relationships was an issue. Staff also raised the challenges that youths face when seeking employment and also the pressures from those around them to drink alcohol and/or to take drugs.

The second theme that emerged from the data was most staff expressed that issues including substance misuse, addiction, and mental health posed the biggest challenges to Bhutanese youths. For substance misuse, drugs and alcohol were the main areas that came up along with smart phone and gaming addiction. For mental health, conditions such as anxiety and depression formed most of the responses. Some examples from the data include responses such as "Depression, anxiety, gaming addiction; leads to attention deficiency and aggressive youths" and "Depression due to some kind of relationship problems (with family, friends and lovers)."

The third theme to emerge from the data gave an insight in to how staff at the RUB view the issues associated with youth identity in Bhutan and the social stigma associated with speaking openly about issues that might be affecting them. Some staff viewed identity issues for Bhutanese youths to be connected with low self-esteem, self-doubt, lack of self-awareness, and low self-confidence. For example, one respondent wrote, "They cannot differentiate what is good and what is not, some cannot take their own decisions [because of] low self-esteem; they feel they cannot do, they are not good at it, etc." Some staff reflected that identity issues are exacerbated by the social stigma that exists in Bhutan around mental health and other issues. One respondent wrote, "Their biggest challenge is not openly showing or discussing their emotions [because of] confusion/conflict in balancing modern vs. traditional values."

The fourth and final theme to emerge from data centered on a minority of staff expressing that being mentally weak was the biggest challenge facing the youth of today in Bhutan. For example, respondents wrote that "Their biggest issue is being emotionally weak and getting influenced very easily" and "Most of our youth give-up easily when faced with a problem, as they have a mental health issue." There was an undertone within this theme that mental health conditions were not a problem when they - the staff - were young. Comparing themselves with the youth of today, some staff believe that today's youth have become less resilient and mentally weaker.

Overall, the data analyzed in this category demonstrates a complex picture of what staff at the RUB believe are the biggest challenges facing the youth of Bhutan today. The four themes showcase a rather mixed picture of opinions that span a wide area. For most staff, anxiety and depression are one of the biggest challenges along with substance misuse and addiction. For other staff, family and relationship problems pose more of a challenge, coupled with a stigma within Bhutanese society that prevents people from being able to speak out about their issues. 
Matthew J. Schuelka, Mollie Braznell, Matthew Leavesley, Sangay Dorji, Khandu Dorji Karma Nidup and Pema Latsho

\section{Category 10: Staff Perception of the Happiness of Students in Bhutan}

When staff were asked about the happiness of Bhutanese youth today - in an open-answer format - three themes emerged from the data. The themes that emerged were benefits of higher education; future prospects; and, society and culture. Each of these themes will be elaborated below.

The first theme that emerged from the data showed that most staff felt student happiness was connected to the free education provided by the Bhutanese government. This included financial subsidies for some courses and scholarships given to Bhutanese youths to attend university. Some examples from the respondents include, "They are happy. Everything is taken care [of]... hostel, food, education...they are loved, cared and listened to" and "I think they are quite happy, because there are very few things to worry about during their studies." Some staff felt that with good campus facilities coupled with on-site support from teachers meant students happiness levels were, overall, very good. Staff also felt that the student lifestyle in Bhutan also elevated their happiness; namely the community feel, socializing with peers and the natural freedoms that come with studying at university.

The second theme that emerged from the staff data found that students worry about their future prospects in regards to employment after graduating. For example, one respondent wrote, "Overall, students are happy when they qualify for a scholarship, but slowly they would not because they begin to think about their future and getting jobs. And there are so many negative influences about previous graduates being left unemployed." The staff who talked about happiness of students linked it with the challenges they face once they complete their studies, namely increased competition in the job market, lack of opportunities, and financial pressures to provide for their families.

The third and final theme that emerged was linked with student happiness and its link with Bhutanese society and culture. Some staff articulated that the Bhutanese way of life gives students the ability to share openly how they feel while being part of a society that together solve problems. For example, one respondent wrote, "In my opinion the college students are happy in Bhutan because they groom, guide and make every youth better prepared for the future and making them shift their vision in line with the values of Gross National Happiness (GNH)." Another respondent wrote, "Yes, [Bhutanese youth are happy] because you get to learn so many things and as all are Bhutanese there is feeling of oneness among them." However, some staff views also aligned themselves to how they viewed pressures for students associated with being a part of Bhutanese society. Other responses included, "Students these days face a lot of social pressure. Pressure to belong to a crowd. Pressure to look good" and "There is pressure to use substances, with little accurate education about the effects. Students also say they have no one they can talk to or depend on."

Overall, the qualitative data provided an insight into how the RUB staff view student happiness. As can be gleaned from the quotes provided, a mixed picture has developed. On the one hand, staff feel that as students receive a free education to study at university as well as good support and facilities on campus, that this equates to overall happiness. However, staff also expressed concern for students' future employment prospects and wider societal pressures that the youth of Bhutan experience today.

\section{Analysis and Comparison of Students and Staff Responses}

For nearly every comparison, staff were generally more pessimistic about students than students were about themselves. None of the differences were deemed to be statistically significant when most questions were analyzed together for each category by running a MANOVA against each of the 4 independent variables. Staff tend to view students as being slightly more depressed than students view themselves to be. However, the mean results for the health and wellbeing category for both student and staff were close in value. Comparing students and staff results also indicate that students perceive their ability to get on well with others somewhat differently to staff, who view them as less capable to get along well with others than they perceive themselves to be. When looking at the mean scores for this category this trend continues as students scored a mean of 6.97 for this category while staff score 6.71. Although these mean scores are not significantly different 
from each other, it does still indicate that staff have a less positive view of student relationships. It is evident that generally staff view students to be less capable than the students perceive themselves to be. Furthermore, the mean score from students from the category was 6.29, whereas the staff survey generated a mean of 5.98 which indicates a difference between student and staff perceptions of student capabilities. However, results also show that staff perceive students to have slightly less anxiety than students view themselves to have.

Comparing the qualitative data sets drew up a mixed picture of results from staff and student views on happiness and mental wellbeing. The most popular response from students in relation to their own happiness centered on the theme of free education. Most of the students that responded to the survey felt their happiness was connected to the free education provided the Bhutanese Government. This was also a common refrain from the analysis of the staff responses. However, a number of students felt that their happiness was dependent upon the facilities provided by the colleges, which some deemed inadequate. Staff did not express any views that attributed happiness to inadequate campus facilities or poor quality of teaching. Staff did report that unhappiness for students was linked to job opportunities and the competitive market that graduates enter in to when leaving university. Students also commonly reported their concerns about lack of job prospects that ultimately effected their happiness whilst at college.

Students and staff were asked about the serious challenges facing the youth of Bhutan. A high number of students noted depression as one of the most serious challenges facing their generation, which was commonly linked to substance misuse. A high number of staff also reported depression and anxiety to be the most serious challenge to Bhutanese youths, concurring the sentiments expressed by the student responses. Staff linked depression and anxiety to family and relationship issues as well as substance misuse, addiction, and the social stigma of talking openly about their feelings.

\section{Discussion: Happiness and Wellbeing in Bhutanese Education and Society}

Using the EVED framework, our analysis of the survey results identifies a number of elements within and without Bhutanese higher education that enable or misalign the promotion of happiness and wellbeing as institutional values.

The first element using the EVED framework are the socio-economic factors that surrounds higher education. One of the major areas of concern for students and staff alike was the anxiety of securing employment after graduation. This anxiety about the future is a somewhat new phenomenon in Bhutan. Before modern education and a modern economy took root in Bhutan in the late $20^{\text {th }}$ century, there was not much choice in terms of employment or education. Most Bhutanese were subsistence farmers and lived their lives hyper-locally. When a modern education system was established in 1959, the explicit purpose of such was human capital development and the prototypes of colleges that would later become consolidated into the RUB existed only within ministries of the Royal Government as employee-feeder organizations. That scenario has completely changed in the $21^{\text {st }}$ century, with employment or vocation not pre-ordained and the future-self insecure. It is certainly a new phenomenon for schools in Bhutan to focus on anything other than academic cognitive skills (Schuelka, Kezang Sherab \& Tsering Y. Nidup, 2019), and this is reflected in our survey in the general dissatisfaction from the students about the facilities and activities that their colleges had to offer that would increase their wellbeing. Youth in Bhutan face the highest unemployment rates and Bhutan finds itself in a situation where the more educated one becomes, the more likely they are to be out work (National Statistics Bureau, 2018). As can be seen in the results of this survey, many students still believe strongly in the narrative of education as a means for social advancement. This belief, based on a narrative myth and not necessarily reality, can actually do more harm in terms of happiness and wellbeing when expectations and scripts do not come to fruition (Kezang Sherab \& Schuelka, forthcoming).

The second element identified using the EVED framework is the importance of community. The results of the survey indicate that both students and staff at the RUB have strong wellbeing 
safety nets and community support. Indeed, this is a strength that exists in Bhutan as a whole. GNH did not simply create happiness and wellbeing out of thin air for the Bhutanese. Rather, it was a reflection of the societal values and cultural norms that already existed. Because of its Buddhist roots, Bhutanese culture features a strong emphasis on harmony. For example, during the COVID-19 pandemic, there was a robust centralized response that received the support and compliance of all Bhutanese citizens. On social media and public health campaigns, the notion of gyenkhu, which transliterally means "our responsibility" in Dzongkha, was widely shared and reflected the complex Bhutanese notion of thinking about their roles and responsibility in society and in how their actions influenced others and the environment.

However rosy gyenkhu and a conscientious culture may be, it can also be difficult to traverse as a young person trying to express themselves and their identities. Within a small, close-knit, and homogenous community, it is difficult to express difference when there is much social pressure to remain the same. This was clearly expressed in the results of our survey. In Bhutan, because of rapid growth and change, there are significant generational gaps that create tension. Youth find it difficult to reconcile what they are learning in school to what their illiterate and agrarian grandparents believe (Kezang Sherab \& Schuelka, forthcoming). So, too, it is difficult for older generations to relate to the challenges that today's Bhutanese youth face. We believe that this is reflected in our survey results in the differences between RUB staff perceptions of students' wellbeing. While many staff responses were sympathetic to challenges faced by modern Bhutanese youth, a significant number of the responses tended to take on a tone of indignation that today's youth 'had it easy' and lamented the corruption of modern Bhutanese youth. In the results of the survey, many staff felt that students 'being weak' was a concern.

The third and fourth elements identified using the EVED framework are materials and teaching. When asked about student happiness, staff and students agreed that students in Bhutan are happy and attributed this to their free education. However, staff also noted facilities to be a positive contributor to their happiness, while students named poor facilities as one of the top reasons for their unhappiness. Furthermore, when students were asked about what academic support they would like, a significant number of respondents cited poor quality teaching which is not something that was mentioned by staff.

Staff and students seemed to share very similar views on mental health challenges and reasons why people experience anxiety and depression. For staff, there was a sense that students need to talk more openly about their issues but at the same time there was a recognition on why that might be difficult. Some staff blamed parents for not being supportive enough to their children and recognized the need for students to receive better parenting. Overall, most staff said that the RUB has all the facilities a student needs to live well and succeed. However, at the same time staff recognized the challenges that students face when they leave university.

\section{Conclusion}

By using the EVED framework to highlight various elements that inform the value of happiness in Bhutanese higher education, it can be seen that there is never just simply any one factor that needs to be addressed. In a complex system, multiple elements need to be addressed in order to make sustainable and systemic change. In this case, happiness in Bhutanese higher education cannot only be taught didactically in a classroom setting, or through policy alone, but it involves addressing community, attitudinal, cultural, and socio-economic factors. Promoting GNH in Bhutanese higher education is a recognition of not only individual lived experiences, but also deliberately putting in place enabling elements across the institutional system. This fully supports the meaning and vision of GNH as a whole.

When asked about the most serious mental health challenges facing the youth of Bhutan, many students were able to provide a response and articulate what they think might cause these issues - substance misuse, employment issues, family/college pressures, among others. However, 
a significant number of respondents simply noted 'depression' when asked about this, providing no further explanation. The results from this question, alongside the other qualitative responses, suggest that students are generally non-dismissive, and have a good perception, of mental health and wellbeing issues. However, their understanding often relies upon personal experience. Those who provided details of their own experiences of mental health and wellbeing issues tended to also demonstrate a far greater understanding.

The staff are aware of mental health conditions, substance misuse and addiction, and can articulate what might cause these challenges. There were some outdated views on what mental health issues are - that they are only for the weak minded - but, generally speaking, staff were mostly empathetic of the needs of the next generation. They recognize job opportunities are poor and family/relationship/financial issues can cause people to suffer. When asked about stress, staff felt overall they did not have much of it. However, other results such as time pressures seemed to contradict this sentiment.

Independent variables were analysed against survey answers: College of study / employment; Age; Gender; Year of study (students) / Years of employment (staff); Non-academic / academic (staff). There were no significant findings from these demographic factors. However, it was clear from the data that the less time staff had worked at RUB, the more stressed they were. This could be seen as normal given it takes time to get the hang of a new job and younger academic staff often are given more to do; but, generally speaking, outdated views - mental health challenges equate to being weak - tended to be from older, more experienced, staff members. The majority of staff (non-teaching and teaching) had comparable answers about mental health challenges and what typically makes students happy.

As a consequence of this study and larger project, student support services at the RUB colleges were integrated into one center called a 'Happiness and Wellbeing Centre'. Prior to this study, different campuses were providing several student wellbeing support services like yoga, mindfulness, and academic skills coordinated by different sources and different experts, hence the activities were not monitored and failed to be sustained in many of the campuses. Therefore, this project provided the opportunity to bridge this gap and integrate all the existing wellbeing support activities under one roof and with the intent to promote GNH more integrally. The results of the survey have reiterated the importance of community support and the role of different stakeholders, both regional and national, in enhancing wellbeing and career guidance that need to further integrate higher education with the socio-economic realities of the community.

\section{Notes}

1 This research was funded through a European Commission Erasmus+ Capacity Building in the Field of Higher Education grant. The full project is titled "Enhancing Mental Health, Counselling, and Wellbeing Support for University Students in Bhutan" (598255-EPP-1-2018-1-BT-EPPKA2-CBHE-JP). The project partners are the Royal University of Bhutan, University of Birmingham (UK), Vrije Universiteit Brussel (Belgium), and Maieutica Cooperativa de Ensino Superior (Portugal).

2 Bhutanese names do not feature family or surnames. Rather, Bhutanese children are named using one or two given names (often given by a Lama or revered Buddhist practitioner), and there is no distinction between 'first names' and 'last names' nor any sense of gendered naming conventions. Therefore, as argued in Schuelka \& Maxwell (2016), Bhutanese scholars should be cited and referenced with their full given name and alphabetized according to the letter of their first (or only) given name.

\section{References}

Braun, V. \& Clarke, V. (2006). Using thematic analysis in psychology. Qualitative Research in Psychology, 3(2), pp.77-101. https://doi.org/10.1191/1478088706qp063oa

Centre for Bhutan Studies (2016). A Compass Towards a Just and Harmonious Society: 2015 GNH Survey Report. Thimphu: Centre for Bhutan Studies and GNH Research.

Creswell, J.W. (2014). Research Design: Qualitative, quantitative, and mixed methods approaches. Thousand Oaks, CA: SAGE. 
Matthew J. Schuelka, Mollie Braznell, Matthew Leavesley, Sangay Dorji, Khandu Dorji Karma Nidup and Pema Latsho

Field, T., Diego, M., Pelaez, M., Deeds, O. \& Delgado, J. (2012). Depression and related problems in university students. College Student Journal, 46(1), pp.193-202.

Gündogdu, M.H. (2010). Life orientations among university students. Egitim ve Bilim, 35(157), p.192-199.

Hasson, D. \& Arnetz, B. B., (2005). Validation and findings comparing VAS vs. Likert Scales for psychosocial measurements. International Electronic Journal of Health Education, 8, pp. 178192.

Jamieson, S. (2004) Likert scales: how to (ab)use them? Medical Education, 38(12), pp. 1217-1218. doi: 10.1111/j.1365-2929.2004.02012.x

Kezang Sherab \& Schuelka, M.J. (forthcoming). Educating for Gross National Happiness: The challenges and opportunities of educational policy and culture in Bhutan. In G. Fry \& H. Chun (Eds.), Happiness Education. London: Routledge.

National Statistics Bureau. (2018). 2017 Population and Housing Census of Bhutan: National Report. Thimphu: National Statistics Bureau of Bhutan.

Pema Thinley (2016). Overview and 'heart essence' of the Bhutanese education system. In M.J. Schuelka \& T.W. Maxwell (Eds.), Education in Bhutan: Culture, schooling, and Gross National Happiness. Singapore: Springer, pp. 19-37. https://doi.org/10.1007/978-981-10-1649-3_2

Rickinson, B. (1998). The relationship between undergraduate student counselling and successful degree completion. Studies in Higher Education, 23(1), pp.95-102. https://doi.org/10.1080/ 03075079812331380522

Schofield, J.W. (2016). Higher education in Bhutan: Progress and challenges. In M.J. Schuelka \& T.W. Maxwell (Eds.), Education in Bhutan: Culture, schooling, and Gross National Happiness. Singapore: Springer, pp. 73-90. https://doi.org/10.1007/978-981-10-1649-3_5

Schuelka, M.J. (2017). Learning at the top of the world: Education policy construction and meaning in Bhutan. In T.D. Jules \& P. Ressler (Eds.), Re-reading Educational Policy and Practice in Small and Micro States.. Bern: Peter Lang, pp. 217-236.

Schuelka, M.J. (forthcoming). Inclusion as a value in a complex educational system: A values and design evaluation of inclusive education in Bhutan. International Journal of Inclusive Education.

Schuelka, M.J. \& Kezang Sherab. (forthcoming). Reform and Alignment in Education Systems: The Educational Values Evaluation and Design Framework. Fora Education.

Schuelka, M.J., Kezang Sherab \& Tsering Y. Nidup (2019). Gross national happiness, British values, and non-cognitive skills: the role and perspective of teachers in Bhutan and England. Educational Review, 71(6), pp. 748-766. https://doi.org/10.1080/00131911.2018.1474175

Schuelka, M.J. \& Maxwell, T.W. (2016). Education in Bhutan: Introduction. In M.J.

Schuelka \& T.W. Maxwell (Eds.), Education in Bhutan: Culture, schooling, and Gross National Happiness. Singapore: Springer, pp. 1-15.https://doi.org/10.1007/978-981-10-1649-3_1

Sonam Kinga. (2005). Youth and Unemployment in Bhutan. In Lham Dorji \& Sonam Kinga (Eds.) Youth in Bhutan: Education, employment. Thimphu, Bhutan: The Centre for Bhutan Studies, pp. 33-79.

Sullivan, G.M., \& Artino, A.R., Jr (2013). Analyzing and interpreting data from likert-type scales. Journal of Graduate Medical Education, 5(4), pp. 541-542. https://doi.org/10.4300/JGME-5-4-18

Williams, G.M., Pendlebury, H., Thomas, K. \& Smith, A.P. (2017). The Student Well-Being Process Questionnaire (Student WPQ). Psychology, 8(11), pp.1748-1761. https://doi.org/10.4236/ psych.2017.811115.

Willis, P. (2003). Foot soldiers of modernity: The dialectics of cultural consumption and the $21^{\text {st }}$ century school. Harvard Educational Review, 73(3), pp.390-415. https://doi.org/10.17763/ haer.73.3.0w5086336u305184

Willits, F.K., Theodori, G.L. \& Luloff, A.E. (2016). Another look at Likert scales. Journal of Rural Social Sciences, 31(3), pp.126-139. 